\title{
Antioxidant and anti-inflammatory activities of ethyl acetate extract of Gynura formosana (Kitam) leaves
}

\author{
JINGFAN MA ${ }^{1-4^{*}}$, CHANG GUO $^{1-3^{*}}$, YINLAI PAN $^{1}$, DANYAN LIN $^{1}$, LONGXIN QIU $^{1-3}$ and LONGPING WEN ${ }^{1,5}$ \\ ${ }^{1}$ Department of Biological Science and Technology, School of Life Sciences, Longyan University; \\ ${ }^{2}$ Key Laboratory of Preventive Veterinary Medicine and Biotechnology (Longyan University), Fujian Province \\ University; ${ }^{3}$ Fujian Provincial Key Laboratory for The Prevention and Control of Animal Infectious Diseases \\ and Biotechnology, Longyan University, Longyan, Fujian 364012; ${ }^{4}$ State Key Laboratory of Chemical Resource \\ Engineering, Beijing 100000; ${ }^{5}$ Hefei National Laboratory for Physical Sciences at The Microscale, School \\ of Life Sciences, University of Science and Technology of China, Hefei, Anhui 230027, P.R. China
}

Received November 10, 2016; Accepted April 21, 2017

DOI: $10.3892 / \mathrm{etm} .2017 .4757$

\begin{abstract}
Gynura formosana Kitam (family Compositae) has traditionally been used for the prevention of diabetes, cancer and inflammation in China. However, there are few reports of its anti-inflammatory effects. In the present study, after assessing the in vitro antioxidant activities of extracts from Gynura formosana Kitam leaves, the anti-inflammatory and antioxidant activities of ethyl acetate extract of Gynura formosana Kitam leaves (EAEG) were further investigated in rats using a cotton pellet-induced model of granuloma. EAEG significantly inhibited the formation of cotton pellet-induced granuloma in rats in a dose-dependent manner. Moreover, EAEG treatment significantly decreased the level of plasma C-reactive protein and suppressed the activities of plasma glutamate pyruvate transaminase and lactate dehydrogenase in model groups. Furthermore, EAEG increased the hepatic levels of anti-oxidative enzymes or antioxidants, including catalase, superoxide dismutase and reduced glutathione, and reduced the level of lipid peroxidation in the rat model of inflammation. In addition, EAEG decreased plasma levels of tumor necrosis factor- $\alpha$ and interleukin- $1 \beta$ in the rat model of inflammation. Therefore, our results indicated that EAEG had potent anti-inflammatory effects, which was achieved at least in part through activating antioxidant enzyme activities and suppressing the production of proinflammatory mediators by macrophages.
\end{abstract}

Correspondence to: Professor Longxin Qiu or Professor Longping Wen, Department of Biological Science and Technology, School of Life Sciences, Longyan University, 1 Dongxiao North Road, Longyan, Fujian 364012, P.R. China

E-mail: 1923015106@qq.com

E-mail: 1pwen@ustc.edu.cn

\section{${ }^{*}$ Contributed equally}

Key words: Gynura formosana Kitam, antioxidant, anti-inflammatory, cotton pellet granuloma

\section{Introduction}

In traditional medicine, medicinal plants or plant-derived products are the most common sources of therapeutic agents; thus, they have an important role in human healthcare. Approximately $80 \%$ of the population in African and Asian countries depends on traditional medicinal plants for their primary healthcare (1). Inflammation is one of the diseases that is usually treated with herbal agents. It is a complex, essential and protective vascular tissue response to invasion by antigen challenge, infectious agents, physical or chemical injury (2). However, prolonged inflammation may cause various chronic diseases, including rheumatoid arthritis and periodontitis and several types of allergic skin diseases (3). Non-steroidal anti-inflammatory drugs are often used to treat inflammatory disease; however, these agents are often associated with side effects, including disturbances to the gastrointestinal tract and aspirin-induced asthma (4). Therefore, there is an increasing need for the development of novel anti-inflammatory agents with fewer side effects than the drugs currently used.

Free radicals are well-known mediators of inflammation, and the free radical-scavenging activities of antioxidants have been documented (5-7). Therefore, plant extracts or phytochemicals with antioxidant activities have been highlighted as promising sources of agent for treating inflammation. Gynura formosana Kitam. (family Compositae) had been traditionally and widely used since the Ming dynasty for the prevention of diabetes, cancer and inflammation in China (8). In the leaves of EAEG, the presence of several components, such as flavonoids, phenolics, alkaloids, saponins and terpenes, has been reported in the literature (9). They may contribute to its biological activity (10). Total phenolics and flavonoids are known as powerful antioxidants and the high contents of phenolic and flavonoid compounds in Gynura formosana Kitam indicate that this plant may exert a beneficial effect on inflammation. However, to the best of our knowledge, the antioxidant and anti-inflammatory activities of this plant have not been reported. Therefore, this study was conducted to investigate the antioxidant and anti-inflammatory effects of ethyl 
acetate extract of Gynura formosana Kitam leaves (EAEG) using a cotton pellet-induced rat model of granuloma.

\section{Materials and methods}

Plant material. Fresh leaves of Gynura formosana Kitam were harvested from the plant greenhouse of Longyan University (Longyan, China) in October 2015, and identified by Professor Yanping Hong of Longyan University.

Preparation of extract. Air-dried leaves were ground homogenously using a 100 mesh mixer-grinder and $200 \mathrm{~g}$ of the samples were soaked in petroleum ether $\left(60-80^{\circ} \mathrm{C}\right)$ at room temperature $\left(25 \pm 1^{\circ} \mathrm{C}\right)$ for $24 \mathrm{~h}$. Petroleum ether extract was subsequently filtered and the residue was extracted twice more in the same manner. The mixture was further filtered, evaporated at $45^{\circ} \mathrm{C}$, and dried in a freeze-dryer for later use. The subsequent residue was successively extracted with chloroform, ethyl acetate and normal butanol in the same way. The yields of petroleum ether, chloroform, ethyl acetate and normal butanol extracts were 9.9, 2.3, 3.2 and 5.8\%, respectively. Extractions were carried out on dry material in order to obtain reproducible results without any interference related to the overall, and variable, water content. All data herein reported were referred to plant dry weight, as generally done when plant extractions were performed (11).

1,1-diphenyl-2-picrylhydrazyl (DPPH) radical scavenging assay. Antioxidant activity determination of the extracts from Gynura formosana Kitam leaves was performed via DPPH radical scavenging according to the method described by Bekir et al (12) with some modifications. Sample solution $(20 \mu \mathrm{l})$ was added to $180 \mu \mathrm{l}$ of freshly prepared DPPH solution. The mixture was incubated and the absorbance was measured at $524 \mathrm{~nm}$. Free radical-scavenging activity was expressed in terms of the half maximal inhibitory concentration $\left(\mathrm{IC}_{50}\right)$. DPPH radical scavenging activity was calculated as a percentage using the equation: DPPH radical scavenging activity $(\%)=\left(\mathrm{A}_{\text {blank }}-\mathrm{A}_{\text {sample }}\right) \times 100 / \mathrm{A}_{\text {blank }}$, where $\mathrm{A}$ is optical density.

\section{2,2-azinobis-3-ethylbenzothiazoline-6-sulphonic acid (ABTS)} radical scavenging assay. ABTS radical scavenging activity was measured spectrophotometrically at $734 \mathrm{~nm}$ according to the modified method of Bekir et al (13). Briefly, $7 \mathrm{mM}$ solution of ABTS was mixed with $2.45 \mathrm{mM}$ potassium persulfate followed by storage in the dark at room temperature for $14 \mathrm{~h}$ before use. In total, $20 \mu \mathrm{l}$ of the different concentrations of extract were reacted with $180 \mu \mathrm{l}$ ABTS solution. Absorbance was measured 6 min after initial mixing. ABTS radical scavenging ability was expressed by $\mathrm{IC}_{50}(\mu \mathrm{g} / \mathrm{ml})$ values determined, as previously described in the DPPH radical scavenging assay.

Experimental animals. A total of 48 male Sprague-Dawley rats (200-250 g) were obtained from the SLAC Laboratory (Shanghai, China). All rats were maintained under a 12-h light/dark cycle at room temperature with free access to food and water. Rats were acclimatized for one week prior to experimentation. Experiments were conducted according to protocols and guidelines approved by Longyan University Institutional Animal Care and Use Committee.

Cotton pellet-induced model of granuloma. The anti-inflammatory effect of EAEG was estimated using a cotton pellet-induced model of granuloma. The method was performed as described by Swingle and Shideman (14) with minor modifications. Rats were randomly assigned to the six groups with 8 rats per group, as follows: Group I, normal control; Group II, model control; Group III, treated with indomethacin (4 mg/kg, standard drug); Group IV, treated with $100 \mathrm{mg} / \mathrm{kg}$ body weight of EAEG orally; Group V, treated with $250 \mathrm{mg} / \mathrm{kg}$ body weight of EAEG orally; and Group VI, treated with $500 \mathrm{mg} / \mathrm{kg}$ body weight of EAEG orally. Sterile cotton pellets $(10 \pm 1 \mathrm{mg})$ were implanted in each axilla region of rats, and the wound was subsequently stitched closed using surgical silk. After $24 \mathrm{~h}$, rats were administered EAEG or indomethacin once daily for 7 days through oral gavage. On the 8th day, blood samples $(2 \mathrm{ml})$ were collected from each rat through retro orbital puncture in EDTA-coated tubes kept in ice, and subsequently centrifuged at $1,000 \mathrm{x}$ g for $20 \mathrm{~min}$ at $4^{\circ} \mathrm{C}$ to separate the plasma. Aliquots were stored at $-80^{\circ} \mathrm{C}$ for proinflammatory cytokine and biochemical estimations. Following sacrifice, the wet cotton pellets from the mice were weighed, followed by drying at $40^{\circ} \mathrm{C}$ for $20 \mathrm{~h}$. The exudate value $(\mathrm{mg})$ was evaluated after deducting the dry weight of the cotton pellet from the wet pellet. Granulation tissue was evaluated by subtracting the weight of the cotton pellet $(10 \pm 1 \mathrm{mg})$ from the dry pellet.

Plasma biochemical analysis. Inflammatory markers, including C-reactive protein (CRP), glutamate pyurvate transaminase (GPT) and lactate dehydrogenase (LDH), were measured in plasma samples using standard ELISA kits (cat no. YD1395 for CRP, cat no. YD1465 for GPT and cat no. 1391 for LDH; YuduoBio Co., Ltd., Shanghai, China), according to the manufacturer's protocols.

Hepatic antioxidant enzymes assay. After eliminating the cotton pellets, liver tissue was dissected and washed with $4^{\circ} \mathrm{C}$ saline to remove the blood. Liver homogenate was centrifuged at $1,280 \mathrm{x} \mathrm{g}$ at $4^{\circ} \mathrm{C}$ for $15 \mathrm{~min}$. The supernatant was used for the evaluation of catalase (CAT) (15), superoxide dismutase (SOD) (16), reduced glutathione (GSH) (17) and malondialdehyde (MDA) (18) levels using assay kits (cat no. A007-2 for CAT, cat no. A001-1 for SOD, cat no. A006-1 for GSH and cat no. A003-1 for MDA; Jiancheng Co., Ltd., Nanjing, China) according to the manufacturer's protocols.

Proinflammatory cytokines analysis. Blood samples were centrifuged at $1,000 \mathrm{x} \mathrm{g}$ at $4^{\circ} \mathrm{C}$ for $10 \mathrm{~min}$ to obtain plasma in order to evaluate tumor necrosis factor- $\alpha$ (TNF- $\alpha$ ) and interleukin-1 $\beta$ (IL-1 $\beta$ ) levels. TNF- $\alpha$ and IL-1 $\beta$ concentrations were quantified using rat TNF- $\alpha$ and IL-1 $\beta$ ELISA kits (cat no. JER-06 for TNF- $\alpha$ and cat no. JER-01 for IL-1 $\beta$; BLKWbio Co., Beijing, China).

Statistical analysis. Results were expressed as the mean \pm standard error of mean. Statistical significances were analyzed by one-way analysis of variance followed by 
A 12

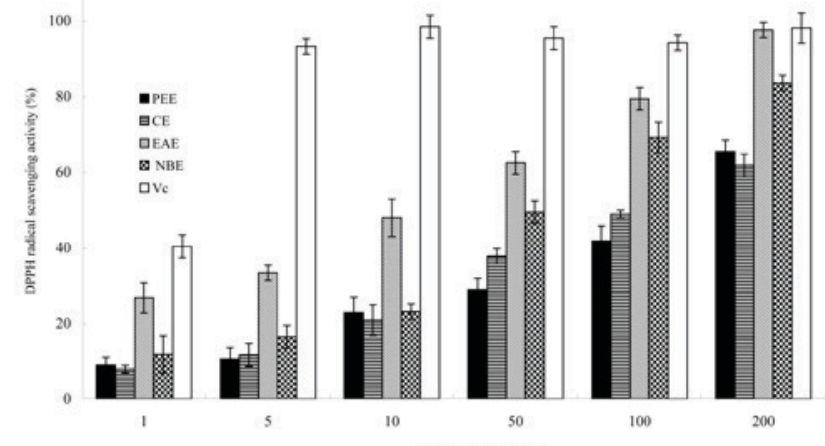

C ${ }^{120}$

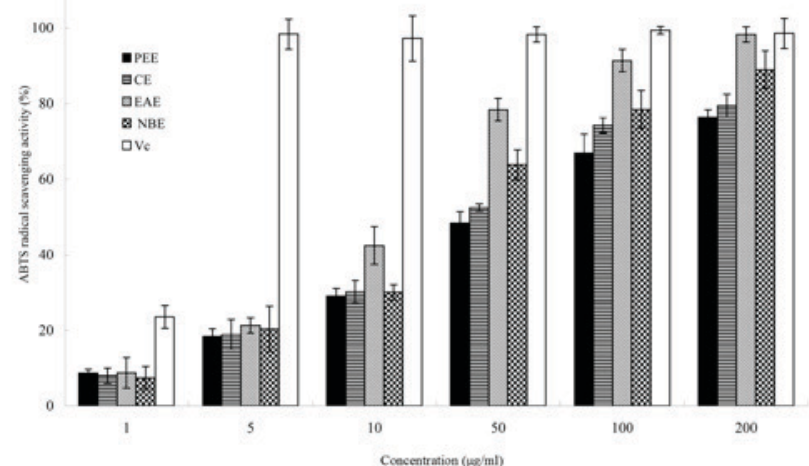

B

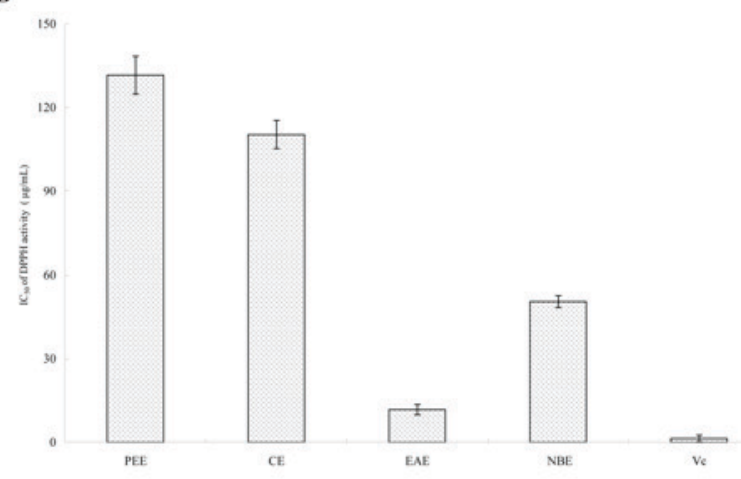

D

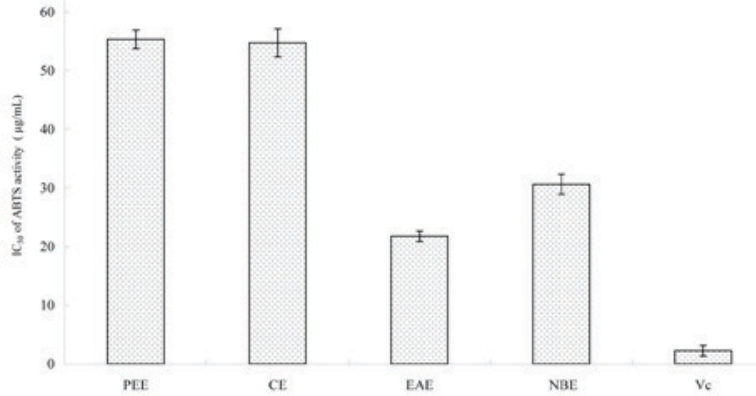

Figure 1. Antioxidant properties of extracts of Gynura formosana Kitam leaves determined using a (A) DPPH radical scavenging assay, (B) $\mathrm{IC}_{50}$ values of $\mathrm{DPPH}$ activity (C) an ABTS radical scavenging assay and (D) $\mathrm{IC}_{50}$ values of ABTS activity. Each bar represents the mean \pm standard error of the mean $(\mathrm{n}=3$ ). PEE, petroleum ether extract; CE, chloroform extract; EAE, ethyl acetate extract; NBE, normal butanol extract; Vc, ascorbic acid.

Dunnett's multiple comparison testing. Statistical analyses were performed using SPSS software (version 22.0; IBM Corp., Armonk, NY, USA). Simple regression analysis was performed to investigate the correlation between ABTS radical scavenging and DPPH radical scavenging using the Microsoft Excel 2010 statistical package (Microsoft Corp., Redmond, WA, USA).

\section{Results}

DPPH and ABTS radicals scavenging activities. To investigate the antioxidant activity of Gynura formosana Kitam, we first determined the in vitro DPPH and ABTS radicals scavenging activities of petroleum ether, chloroform, ethyl acetate and normal butanol extracts of Gynura formosana Kitam leaves. As shown in Fig. 1A, extracts of Gynura formosana Kitam leaves exhibited strong DPPH radical scavenging activities. All of the samples exhibited dose-dependent activity. In this experiment, the $\mathrm{IC}_{50}$ for petroleum ether extract (PEE), chloroform extract (CE), ethyl acetate extract (EAE), normal butanol extract (NBE) and ascorbic acid (Vc) were $131.67 \pm 6.72,110.36 \pm 5.11,11.77 \pm 1.83,50.46 \pm 2.13$, and $1.39 \pm 0.03 \mu \mathrm{g} / \mathrm{ml}$, respectively (Fig. 1B). ABTS radical scavenging activities of Gynura formosana Kitam's leaves extracts are presented in Fig. $1 \mathrm{C} . \mathrm{IC}_{50}$ values for PEE, CE, EAE, NBE and $\mathrm{Vc}$ were $55.37 \pm 1.56,54.79 \pm 2.37,21.82 \pm 0.88$, $30.67 \pm 1.68$, and $2.24 \pm 0.02 \mu \mathrm{g} / \mathrm{ml}$, respectively (Fig. 1D).
These findings demonstrated that the maximum radical scavenging activities were in EAE followed by NBE, CE and PEE. Therefore, EAE was selected for further investigation of its antioxidant and anti-inflammatory effects in an animal model.

Effect of EAEG on granuloma weight in rats inflammation model. Rodent models of cotton pellet induced granuloma have been widely used to evaluate the anti-inflammation activities of chemicals $(19,20)$. To investigate the anti-inflammatory activity of EAEG, we studied the effect of EAEG on cotton pellet-induced granuloma in rats. Cotton pellets removed from the rats at the end of the study are presented in Fig. 2A. The anti-inflammatory effect of EAEG was determined by the wet and dry granuloma weight in rats and the results are summarized in Fig. 2B. EAEG exhibited a significant $(\mathrm{P}<0.05)$ and dose-related inhibition of granuloma formation when compared with the model control group. Among the three test dose levels of EAEG, the dose of $250 \mathrm{mg} / \mathrm{kg}$ was found to be equally potent as to that of indomethacin $(4 \mathrm{mg} / \mathrm{kg})$.

Plasma biochemical markers assay. Levels of plasma inflammatory biomarkers (LDH, GPT and CRP) were significantly $(\mathrm{P}<0.01)$ increased in model control rats when compared with the normal group, whereas these markers exhibited significantly $(\mathrm{P}<0.05)$ decreased activity after treatment with 100,250 and $500 \mathrm{mg} / \mathrm{kg}$ EAEG and $4 \mathrm{mg} / \mathrm{kg}$ indomethacin, 

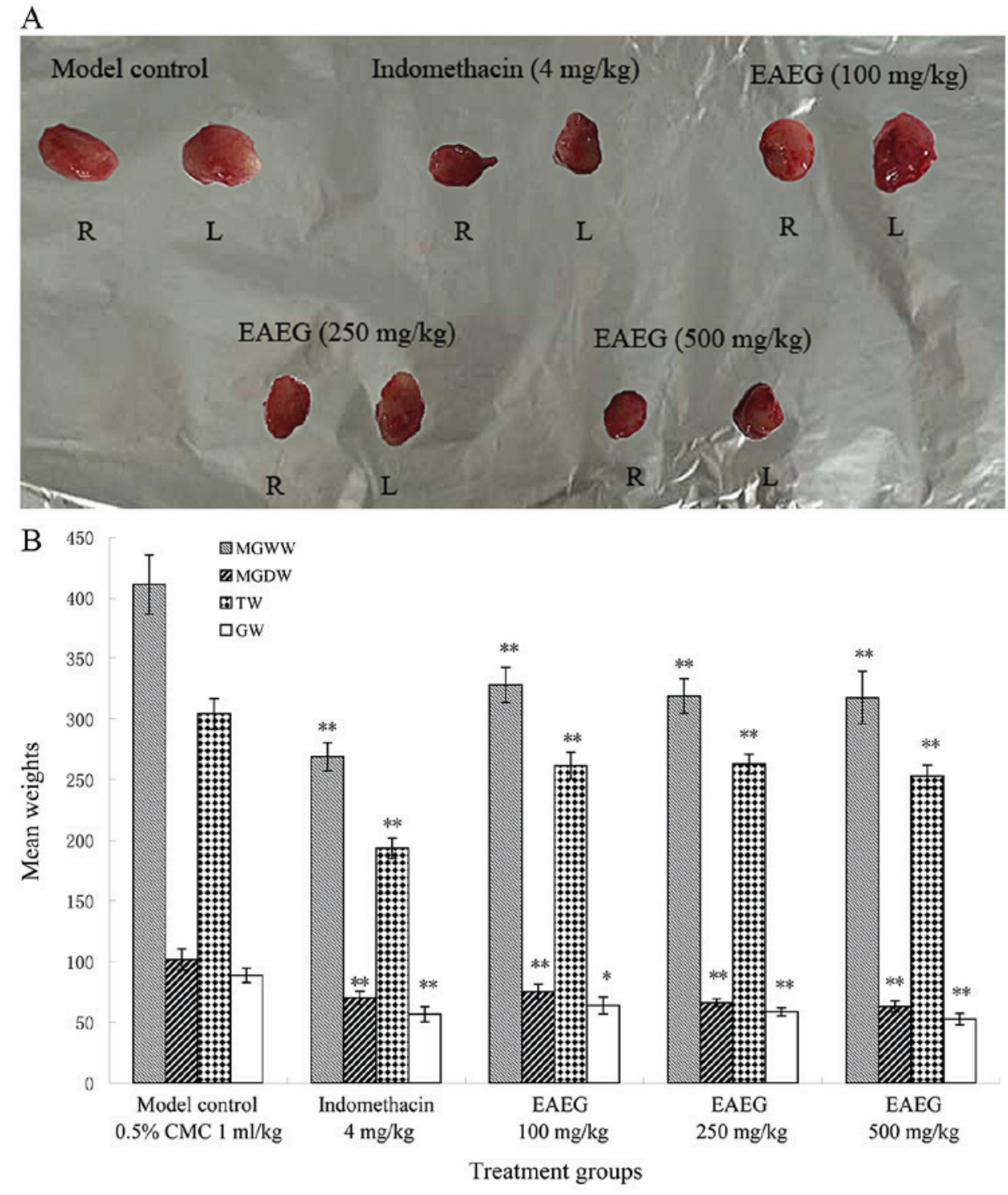

Figure 2. (A) Exposed cotton pellets and (B) granuloma weight in in rat models of cotton pellet-induced granuloma. Results are expressed as the mean \pm standard error of the mean $(\mathrm{n}=8)$. ${ }^{*} \mathrm{P}<0.05$ and ${ }^{* * *} \mathrm{P}<0.01$ vs. the model control group. R, right cotton; L, left cotton; EAEG, ethyl acetate extract of Gynura formosana Kitam leaves; MGWW, mean of granuloma wet weight (mg); MGDW, mean of granuloma dry weight (mg); TW, transudative weight (mg); GW, granuloma weight (mg); CMC, carboxymethylcellulose.

respectively (Fig. 3). In addition, EAEG at dose of 250 and $500 \mathrm{mg} / \mathrm{kg}$ showed no significant difference in activity in comparison with normal rats.

Effect of EAEG on hepatic antioxidants in rat models with cotton pellet-induced granuloma. To investigate the antioxidant effect of EAEG in vivo, we further studied the effect of EAEG on the activities of CAT, SOD, GSH and the level of lipid peroxidation in the livers of rats with cotton pellet-induced granuloma. The model control group exhibited coincidently significant $(\mathrm{P}<0.01)$ decreases in the activities of CAT, SOD, GSH and an increase in the level of lipid peroxidation in the liver (Fig. 4). EAEG treatment at doses of 250 and $500 \mathrm{mg} / \mathrm{kg}$ induced a significant increase in the activities of CAT $(\mathrm{P}<0.01)$, SOD $(\mathrm{P}<0.05$ and $\mathrm{P}<0.01$ respectively) and GSH $(\mathrm{P}<0.01)$ and decrease in lipid peroxidation $(\mathrm{P}<0.01)$ in the rat liver, when compared with the model control group. Indomethacin did not exhibit any significant changes in antioxidant levels in the rat liver when compared with the model control group.

Effect of EAEG on plasma levels of proinflammatory cytokines. Proinflammatory cytokines have a central function in the maintenance of chronic inflammation; therefore, plasma levels of TNF- $\alpha$ and IL-1 $\beta$ were evaluated in the present experiment. Fig. 5 shows that the plasma levels of TNF- $\alpha$ and IL-1 $\beta$ in the model control group were significantly higher than those in the normal control group $(\mathrm{P}<0.01)$. TNF- $\alpha$ and IL-1 $\beta$ levels were significantly decreased in the EAEG-treated groups, as compared to the model control group, in a dose-dependent manner $(\mathrm{P}<0.05)$. Indomethacin $(4 \mathrm{mg} / \mathrm{kg})$ also significantly $(\mathrm{P}<0.05)$ inhibited the production of TNF- $\alpha$ and IL-1 $\beta$. The inhibitory activity of EAEG $(250 \mathrm{mg} / \mathrm{kg})$ against TNF- $\alpha$ was similar to that of indomethacin $(4 \mathrm{mg} / \mathrm{kg})$. Notably, a low concentration of EAEG $(100 \mathrm{mg} / \mathrm{kg})$ in our experiment was more 


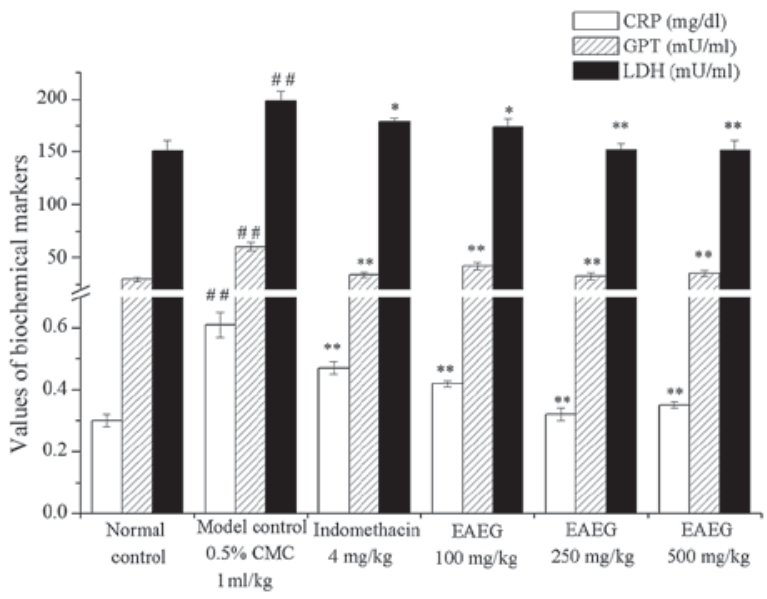

Figure 3. Effect of EAE on plasma levels of biochemical markers in rat models of cotton pellet-induced granuloma. Results are expressed as the mean \pm standard error of the mean $(n=8) .{ }^{\# \#} \mathrm{P}<0.01$ vs. the normal control group; ${ }^{*} \mathrm{P}<0.05$ and ${ }^{* *} \mathrm{P}<0.01$ vs. the model control group. CRP, C-reactive protein; GPT, glutamate pyurvate transaminase; LDH, lactate dehydrogenase; CMC, carboxymethylcellulose; EAEG, ethyl acetate extract of Gynura formosana Kitam leaves.

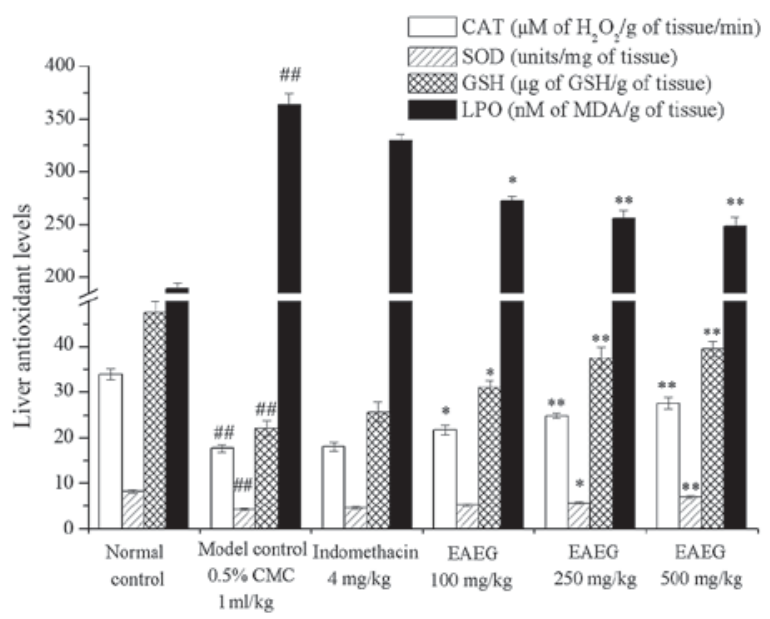

Figure 4. Effect of EAEG on liver antioxidant levels in rat models of cotton pellet-induced granuloma. Values are expressed as the mean \pm standard error of the mean $(\mathrm{n}=8)$. ${ }^{\# \#} \mathrm{P}<0.01$ vs. the normal control group; ${ }^{*} \mathrm{P}<0.05$ and ${ }^{* *} \mathrm{P}<0.01$ vs. the model control group. CMC, carboxymethylcellulose; EAEG, ethyl acetate extract of Gynura formosana Kitam leaves; CAT, catalase; SOD, superoxide dismutase; GSH, reduced glutathione; MDA, malondialdehyde; LPO, lipid peroxide.

effective at inhibiting IL-1 $\beta$ production than indomethacin $(4 \mathrm{mg} / \mathrm{kg})$.

\section{Discussion}

Cotton pellet-induced granuloma is a reliable in vivo model for studying inflammation and proliferation due to inflammation (21). Inflammatory reactions in cotton pellet-induced granuloma model involve the proliferation of macrophages, fibroblasts and granulocyte infiltration (22). The fluid absorbed by the cotton pellet greatly influences the wet weight of the granuloma, whereas the dry weight correlates with the weight of the granulomatous tissue (23). The findings of the present study demonstrated that treatment with EAEG inhibited

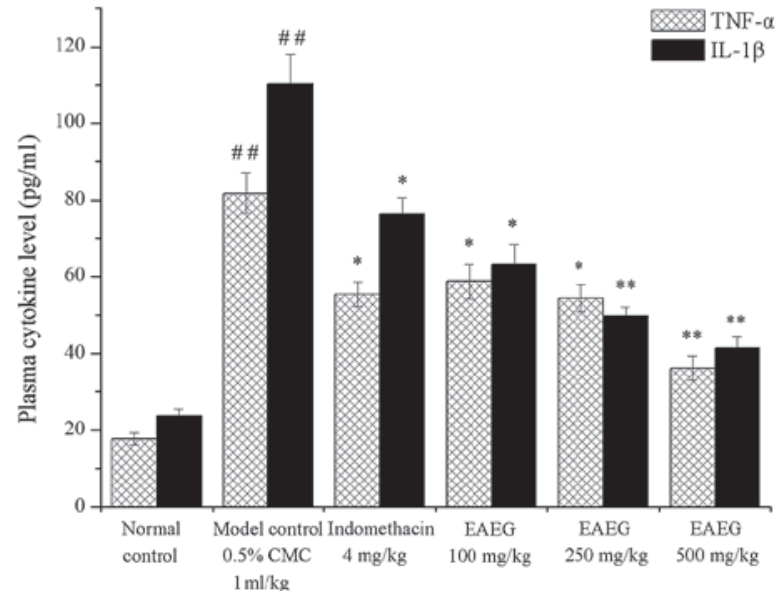

Figure 5. Effect of EAE on plasma levels of proinflammatory cytokines in rat models of cotton pellet-induced granuloma. Values are expressed as the mean \pm standard error of the mean $(\mathrm{n}=8)$. ${ }^{\# \#} \mathrm{P}<0.01$ vs. the normal control group; ${ }^{*} \mathrm{P}<0.05$ and ${ }^{* *} \mathrm{P}<0.01$ vs. the model control group. CMC, carboxymethylcellulose; EAEG, ethyl acetate extract of Gynura formosana Kitam leaves; TNF, tumor necrosis factor; IL, interleukin.

the transudation and proliferation of inflammation to some extent, similar to indomethacin therapy. As a non-steroidal anti-inflammatory drug, indomethacin produces its inhibitory effect in cotton pellet-induced granuloma experiment by inhibiting granulocyte infiltration to the cotton pellet and preventing the generation of collagen fibers (24). The result that EAEG significantly decreased the weight of the cotton pellet-induced granuloma in the model control group suggested that EAEG is a natural anti-proliferative substance of granulation formation and has the potential to improve inflammation reactions.

We assayed the levels of CRP, GPT and LDH in rat plasma to further evaluate the anti-inflammatory activity of EAEG. CRP is a known marker of inflammation, and it is also considered to be an active participant in promoting endothelial dysfunction by reducing the expression of L-selectin and generation of the superoxide (25). The significant decrease in CRP concentrations in the EAEG-treated rats with cotton pellet-induced granuloma suggested that EAEG improved endothelial dysfunction, thereby preventing the occurrence of further adverse events, including cell membrane transmigration and disintegration in the inflammatory response. GPT has an important role in the formation of biologically active chemical mediators, such as kinins, in the inflammatory response (26). LDH is a cytoplasmic enzyme present in the extra cellular space. It has no relevant metabolic function, but serves as an indicator of the disturbance of cellular integrity in the inflammatory response. Levels of GPT and LDH increased in the model control group, whereas these levels decreased in the indomethacin- and EAEG-treated groups, suggesting a reduction in bradykinins release and membrane stabilizing potential. These data demonstrate the anti-inflammatory activities of EAEG. To the best of our knowledge, this is the first report of the anti-inflammatory activities of Gynura formosana Kitam leaf extracts.

It is well-established that various free radicals, including DPPH, ABTS radicals and superoxide, and other reactive species, such as singlet oxygen, hypochlorous acid and peroxynitrite, contribute to the pathology of chronic 
inflammation $(27,28)$. Previous studies have suggested that inflammatory tissue damage may be due to the liberation of reactive oxygen species from the phagocytes that invade inflammation sites $(29,30)$. DPPH and ABTS radical scavenging assays, based on electron transfer and hydrogen atom transfer reaction, are analytical methods for the reliable determination of antioxidant activities of biological samples in vitro (31). In this study, samples from the EAEG treatment groups exhibited significant DPPH and ABTS radical scavenging activities and these results suggested that free radicals scavenging activities contribute to the antioxidant effects of EAEG in vitro, which may be responsible for its anti-inflammatory activities (32).

A balance exists between free radicals and natural scavengers in normal states. Elevated production of oxygen free radicals is observed during inflammation, in which relatively low activities of antioxidant enzymes, such as SOD and CAT, cause cell membrane disturbance and damage to cells in the tissues. Lipid peroxidation is an oxidative deterioration reaction that may alter the polyunsaturated lipids to radical intermediates and subsequently cause cellular damage. MDA is a major end-product of this reaction, and a marker of lipid peroxidation (33). In this study, CAT, SOD, GSH and MDA were assayed in liver tissues of rats treated with EAEG to further investigate the antioxidant mechanisms underlying the protective effects of Gynura formosana Kitam leaves on inflammation. In the model control group, there was a decrease in the activities of CAT, SOD and GSH and an increase in the levels of MDA; however, treatment with EAEG was found to increase the activities of antioxidants (CAT, SOD and GSH) and decrease the level of MDA in the rat liver. These data demonstrated the involvement of antioxidants in the mechanisms whereby Gynura formosana Kitam leaves extracts protect against inflammation.

Activated proinflammatory macrophages produce and release various substances, including proinflammatory cytokines (such as TNF- $\alpha$ and IL-1 $\beta$ ) and prostaglandins, which amplify the inflammatory cascade and result in the formation of granulomas, inflammatory lesions and subsequent tissue damage $(34,35)$. Most of plant extracts that are widely known to exert anti-inflammatory effects have been studied for their potential to inhibit proinflammatory cytokines (36). Therefore, the inhibitory effects of EAEG on proinflammatory cytokines (TNF- $\alpha$ and IL-1 $\beta$ ) were evaluated. TNF- $\alpha$ is a key mediator of inflammation and a pleiotropic inflammatory cytokine produced by the immune system. IL- $1 \beta$ is a prototypical proinflammatory cytokine that stimulates both local and systemic responses; it is also known as leukocyte endogenous mediator, endogenous pyrogen, lymphocyte activating factor and mononuclear cell factor. Inhibiting the production of TNF- $\alpha$ and IL-1 $\beta$ may reduce infiltration of inflammatory cells into the tissue (37). We demonstrated a significant reduction in the levels of TNF- $\alpha$ and IL-1 $\beta$ in EAEG-treated groups, as compared with the model control group. The reduction of TNF- $\alpha$ and IL-1 $\beta$ levels in EAEG-treated groups suggests that the protective effect of EAEG against inflammation may be associated with the downregulation of TNF- $\alpha$ and IL-1 $\beta$ production.

In conclusion, the present data demonstrated that Gynura formosana Kitam leaf is a natural source of antioxidants and may exert beneficial effects against inflammation by scavenging free radicals, activating antioxidant enzymes and by suppressing the production of proinflammatory mediators by macrophages. These findings provide a scientific basis for the traditional use of Gynura formosana Kitam for treating chronic inflammation. However, EAEG requires further investigation in order to identify the active ingredients and elucidate its mechanisms of action.

\section{Acknowledgements}

This study was funded by the State Key Laboratory of Chemical Resource Engineering and Longyan University (grant no. LG2014014) and the Training Program of FuJian Excellent Talents in University (grant no. MJR201558).

\section{References}

1. Ezuruike UF and Prieto JM: The use of plants in the traditional management of diabetes in Nigeria: Pharmacological and toxicological considerations. J Ethnopharmacol 155: 857-924, 2014.

2. Miri A, Sharifi-Rad J, Tabrizian K and Nasiri AA: Antinociceptive and anti-inflammatory activities of Teucrium persicum Boiss. Extract in Mice. Scientifica (Cairo) 2015: 972827, 2015.

3. Hajhashemi V, Sajjadi SE and Heshmati M: Anti-inflammatory and analgesic properties of Heracleum persicum essential oil and hydroalcoholic extract in animal models. J Ethnopharmacol 124: 475-480, 2009.

4. Akah P, Okolo CE and Ezike A: The haematinic activity of the methanol leaf extract of Brillantasia nitens Lindau (Acanthaceae) in rats. Afr J Biotechnol 8: 2389-2393, 2009.

5. Owoyele VB, Wuraola CO, Soladoye AO and Olaleye SB: Studies on the anti-inflammatory and analgesic properties of Tithonia diversifolia leaf extract. J Ethnopharmacol 90: 317-321, 2004.

6. Simirgiotis MJ, Bórquez J and Schmeda-Hirschmann G: Antioxidant capacity, polyphenolic content and tandem HPLC-DAD-ESI/MS profiling of phenolic compounds from the South American berries Luma apiculata and L. chequén. Food Chem 139: 289-299, 2013.

7. Ismail HI, Chan KW, Mariod AA and Ismail M: Phenolic content and antioxidant activity of cantaloupe (Cucumis melo) methanolic extracts. Food Chem 119: 643-647, 2010.

8. Wang YB and Li CG: High yield cultivation techniques of Gynura formosana (Kitam). Hubei Lin Ye Ke Ji 2: 73-74, 2010 (In Chinese).

9. Hou WC, Lin RD, Lee TH, Huang YH, Hsu FL and Lee MH: The phenolic constituents and free radical scavenging activities of Gynura formosana Kiamnra. J Sci Food Agric 85: 615-621, 2005.

10. Seow LJ, Beh HK, Sadikun A and Asmawi MZ: preliminary phytochemical and physicochemical characterization of Gynura segetum (Lour) Merr (Compositae) Leaf. Trop J Pharm Res 12: 777-782, 2013.

11. Locatelli M, Genovese S, Carlucci G, Kremer D, Randic M and Epifano F: Development and application of high-performance liquid chromatography for the study of two new oxyprenylated anthraquinones produced by Rhamnus species. J Chromatogr A 1225: 113-120, 2012.

12. Bekir J, Mars M, Souchard JP and Bouajila J: Assessment of antioxidant, anti-inflammatory, anti-cholinesterase and cytotoxic activities of pomegranate (Punica granatum) leaves. Food Chem Toxicol 55: 470-475, 2013.

13. Bekir J, Mars M, Vicendo P, Fterrich A and Bouajila J: Chemical composition and antioxidant, anti-inflammatory, and antiproliferation activities of pomegranate (Punica granatum) flowers. J Med Food 16: 544-550, 2013.

14. Swingle KF and Shideman FE: Phases of the inflammatory response to subcutaneous implantation of a cotton pellet and their modification by certain anti-inflammatory agents. J Pharmacol Exp Ther 183: 226-234, 1972.

15. Colowick SP, Kaplan NO and Packer L: Methods in enzymology. Academic Press London 105: 121-125, 1984.

16. Misra HP and Fridovich I: The role of superoxide anion in the autoxidation of epinephrine and a simple assay for superoxide dismutase. J Biol Chem 247: 3170-3175, 1972.

17. Ellman GL: Tissue sulfhydryl groups. Arch Biochem Biophys 82: 70-77, 1959. 
18. Slater TF and Sawyer BC: The stimulatory effects of carbon tetrachloride and other halogenoalkanes on peroxidative reactions in rat liver fractions in vitro. General features of the systems used. Biochem J 123: 805-814, 1971.

19. Afsar SK, Kumar KR, Gopal JV and Raveesha P: Assessment of anti-inflammatory activity of Artemisia vulgaris leaves by cotton pellet granuloma method in Wistar albino rats. J Pharm Res 7: 463-467, 2013.

20. Marroquin-Segura R, Flores-Pimentel M, Carreón-Sánchez R, Garcia-Burciaga MM, Mora-Guevara JL, Aguilar-Contreras A and Hernandez-Abad VJ: The effect of the aqueous extract of helietta parvifolia A. Gray (rutaceae) stem bark on carrageenan-induced paw oedema and granuloma tissue formation in mice. J Ethnopharmacol 124: 639-641, 2009.

21. Saeed N, Khan MR and Shabbir M: Antioxidant activity, total phenolic and total flavonoid contents of whole plant extracts Torilis leptophylla L. BMC Complement Altern Med 12: 221 , 2012.

22. Nair V, Kumar R, Singh S and Gupta YK: Investigation into the anti-inflammatory and antigranuloma activity of Colchicum luteum Baker in experimental models. Inflammation 35: 881-888, 2012.

23. Chouhan HS and Singh SK: Phytochemical analysis, antioxidant and anti-inflammatory activities of Phyllanthus simplex. J Ethnopharmacol 137: 1337-1344, 2011.

24. Valderramas AC, Moura SHP, Couto M, Pasetto S and Chierice GO: Antiinflammatory activity of Ricinus communis derived polymer. Braz J Oral Sci 7: 1666-1672, 2008.

25. Janakiraman M: Phytochemical studies on Laurencia obtusa (hudson) lamourux. Int J Biomed Adv Res 3: 225-232, 2012.

26. Gabay $\mathrm{C}$ and Kushner I: Acute-phase proteins and other systemic responses to inflammation. N Engl J Med 340: 448-454, 1999.

27. Li WF, Hao DJ, Fan T, Huang HM, Yao H and Niu XF: Protective effect of chelerythrine against ethanol-induced gastric ulcer in mice. Chem Biol Interact 208: 18-27, 2014.
28. Tsai YD, Hsu HF, Chen ZH, Wang YT, Huang SH, Chen HJ, Wang CP, Wang SW, Chang CC and Houng JY: Antioxidant, anti-inflammatory, and anti-proliferative activities of extracts from different parts of farmed and wild Glossogyne tenuifolia. Ind Crop Prod 57: 98-105, 2014.

29. Liang H, He J, Ma AG, Zhang PH, Bi SL and Shi DY: Effect of ethanol extract of alga Laurencia supplementation on DNA oxidation and alkylation damage in mice. Asia Pac J Clin Nutr 16 (Suppl 1): 164-168, 2007.

30. Conner EM and Grisham MB: Inflammation, free radicals, and antioxidants. Nutrition 12: 274-277, 1996.

31. Roy P, Amdekar S, Kumar A and Singh V: Preliminary study of the antioxidant properties of flowers and roots of Pyrostegia venusta (Ker Gawl) Miers. BMC Complement Altern Med 11: 69, 2011.

32. Lee DB, Kim DH and Je JY: Antioxidant and cytoprotective effects of lotus (Nelumbo nucifera) leaves phenolic fraction. Prev Nutr Food Sci 20: 22-28, 2015

33. Choi JH, Jung BH, Kang OH, Choi HJ, Park PS, Cho SH, Kim YC, Sohn DH, Park H, Lee JH and Kwon DY: The anti-inflammatory and anti-nociceptive effects of ethyl acetate fraction of cynanchi paniculati radix. Biol Pharm Bull 29: 971-975, 2006.

34. Glenn EM, Gray J and Kooyers W: Chemical changes in adjuvant-induced polyarthritis of rats. Am J Vet Res 26: 1195-1203, 1965.

35. Levine S, Smith VV, Malone M and Sebire NJ: Histopathological features of chronic granulomatous disease (CGD) in childhood. Histopathology 47: 508-516, 2005.

36. Scott A, Khan KM, Roberts CR, Cook JL and Duronio V: What do we mean by the term 'inflammation'? A contemporary basic science update for sports medicine. Br J Sports Med 38: 372-380, 2004.

37. Gabay C, Lamacchia C and Palmer G: IL-1 pathways in inflammation and human diseases. Nat Rev Rheumatol 6: 232-241, 2010. 